\title{
Decision Support System for Flood Protection of Critical Infrastructure Facilities Based on Water Intake Map
}

\author{
Magdalena Kwiecień*, Tomasz Walczykiewicz \\ Institute of Meteorology and Water Management, Division of Water Management, National Research Institute, \\ Piotra Borowego 14, 30-215 Cracow, Poland \\ Received: 13 August 2014 \\ Accepted: 23 September 2014

\begin{abstract}
This article presents one of the tools developed in Poland within the framework of the IT system for national protection against extreme hazards. The Water Intakes Monitor, created as a part of the project, is a decision support system that aids the protection of water intakes should they be threatened with flooding. The Water Intakes Monitor and the operational map of surface water and groundwater intakes in areas where floods may occur, present the risk of possible water intake inundation and hazards associated with it. The information on the threat is presented as a water intake status determined by a forecast stream bed expressed as a percentage. Additionally, the application allows us to display supplementary information on current and forecasted hydrometeorological situations and combines it with information provided by flood risk maps.
\end{abstract}

Keywords: critical infrastructure, flood, water intakes, warning system

\section{Introduction}

The current approach to flood protection, which has focused mainly on limiting areas threatened by flooding, has been replaced with a strategy of reducing the negative effects of said phenomenon. This transformation requires recognition that flood occurrences are inevitable and that safety needs to be guaranteed along with developmental requirements [1].

This new approach was confirmed by Directive 2007/60/EC of the European Parliament and of the Council of 23 October 2007 on the assessment and management of flood risks [2]. The Directive introduced a definition of a flood risk, which in many countries is the basis for actions reducing the consequences of floods and losses caused by them.

Surface water and groundwater intakes, as the facilities of critical infrastructure, are essential sites that should be

\footnotetext{
*e-mail: magdalena.kwiecien@imgw.pl
}

protected from flood consequences. The European Programme for Critical Infrastructure Protection was announced in the EU European Commission Communication COM (2006) 786 [3]. This suggested that a directory of the facilities constituting the critical infrastructure is based on suggestions made by the member states. Council Directive 2008/114/EC [4] establishes a procedure for the identification and designation of the critical infrastructure elements. The Critical Infrastructure analysis should cover:

- Identification of important assets

- Conducting risk analysis based on major threat scenarios and the vulnerability of each asset

- Analysis of potential impacts

- Identification, selection, and prioritization of countermeasures and procedures

A communication of the Commission to the European Parliament and the Council (the EU Internal Strategy in Action [5]) outlined major challenges for European Union safety to be fulfilled until 2014, presented as five steps 
toward a more secure Europe. One of them is to increase Europe's resilience to crises and disasters. The communication stresses the importance of better risk assessment and risk management at the EU level for all potential hazards, including floods.

For water intakes and facilities related to them, the following phases of flood risk management can be determined for dealing with the flooding phenomenon:

- Prevention - continuous monitoring of hazards and application of proactive actions, including monitoring of water intakes and water treatment plants

- Reaction - taking actions to shut down threatened facilities, launching alternative methods of water supply, and active control of the situation associated with the ability of having control over and eliminating the event

- Reconstruction - bringing the disabled constituents of the system back online, and coordinating the work of teams responsible for efficient recovery from damage and their consequences in the least possible amount of time

In Poland, the protection of surface water and groundwater intakes from the consequences of flooding is one of the objectives of the IT System of Country Protection against Extreme Hazards (ISOK) [6]. The ISOK project is cofinanced by the European Regional Development Fund as a part of the Innovative Economy Operational Programme (Priority Axis 7 - Information Society). Its implementation is planned for 2010-14. The system will be used to increase national safety and reduce losses caused by natural, technological, and synergistic hazards. The main use of the system is then supporting the protection of society, the economy, and the environment against extreme hazards; another is to aid decision making should extremes occur. Besides, ISOK will posses tools (applications) allowing it to support routine and incidental tasks required for managing, updating, and processing data (for example giving information on the status of a given threat, carrying out analyses using geospatial information, generating reports, etc.).

One of the applications supporting decision making was designed at the Institute of Meteorology and Water Management at the National Research Institute (IMGWPIB) ${ }^{1)}$ for water intakes protection. The application was created for displaying a map of surface water and groundwater intakes for areas threatened with flood occurrences (water intake map).

The application described in this article consolidates the IMGW-PIB research experiences resulting from streamflow hydraulic modelling with the use of information technologies. The IMGW-PIB scientific as well as research and implementation works were heretofore aimed at the development of a hydrometeorological service. Thanks to the ISOK project it was possible to obtain solutions which, by applying meteorological, hydrological and IT knowledge, will support other members of the emergency management process as well as subjects vulnerable to the consequences of flood negative effects.

\section{Location of Water Intake Map in the ISOK Project and among Other Warning Systems}

During floods, water intakes within the range of flood waters cannot operate and there is a risk of their contamination by pollutants carried with waters and washed from the ground [7]. It is important to provide adequate alternative solutions connected with a water supply or its reserve as well as community awareness and quick access to information on the current hazard [8]. Flood-related losses in Europe are gradually increasing, and social factors are the main cause [9]. In Poland, after the flood in 2010 the estimated losses in the water intake infrastructure reached nearly $€ 4$ million [10]. According to data from the National Sanitary Inspectorate [11], during the flood there were 396 examples of water intakes and accompanying infrastructure shutdowns. The creation of warning systems and modeling flood hazards are the foundation of response systems; early response systems are also developed for smaller drainage basins [12]. The development of numerical methods of weather forecasting provides the basis for the advance in various solutions for warning systems in Europe [13].

In Poland, too, independent of the hydrometeorological protection provided by the IMGW-PIB, it was decided to compile a register of obtainable operational maps of risk as distinct decision support systems. The maps concerned meteorological as well as other hazards conditioned by hydrometeorological phenomena. In a case study for the ISOK project it was emphasized that the lack of such maps not only impedes all preventative actions, but it also affects the preparation of public authorities, services, and forces for taking effective action. It was also decided that within the framework of the ISOK project there will be no possibility of creating all possible maps; however, the IT system developed alongside will be the basis for further expansion after the project is finished. The two following charts show the place of the component among maps of other hazards included in the ISOK project (Fig. 1), and maps of other hazards chosen for its development (Fig. 2).

\section{Characteristics of Water Intake Maps: Experimental Procedures}

Water intake maps, in accordance with previously accepted guidelines, are the expansion of flood hazard maps developed under Directive 2007/60/EC (Fig. 3).

\footnotetext{
Institute of Meteorology and Water Management, National Research Institute (IMGW-PIB) [4], is a research-development unit constituted by resolution No. 338/72 Cabinet of 30 December 1972 on merging the State Hydrological Institute with the Institute of Water Management, operating in compliance with the Act of 25 July 1985 on research and development units. The purpose of the institute is satisfying the needs of society, the national economy, and national defense within the scope of its statutory duty. The institute realizes this duty through conducting research, development, and implementing operations, as well as by maintaining observational and measurement networks, carrying out observations and measurements, and developing forecasts and expertise.
} 
Chosen surface water and groundwater intakes threatened with flooding are particularized with the information on the consequences of their possible shutdown. The information contains, inter alia, hourly maximum yield $\left[\mathrm{m}^{3} / \mathrm{h}\right]$, yield purpose, number of households supplied by the water sup- ply network, and the existence of alternative water intake sources. Such maps possess an operational nature, depicting intakes with background information on current and forecasted hydrometeorological situations and linking to information provided by flood risk maps.

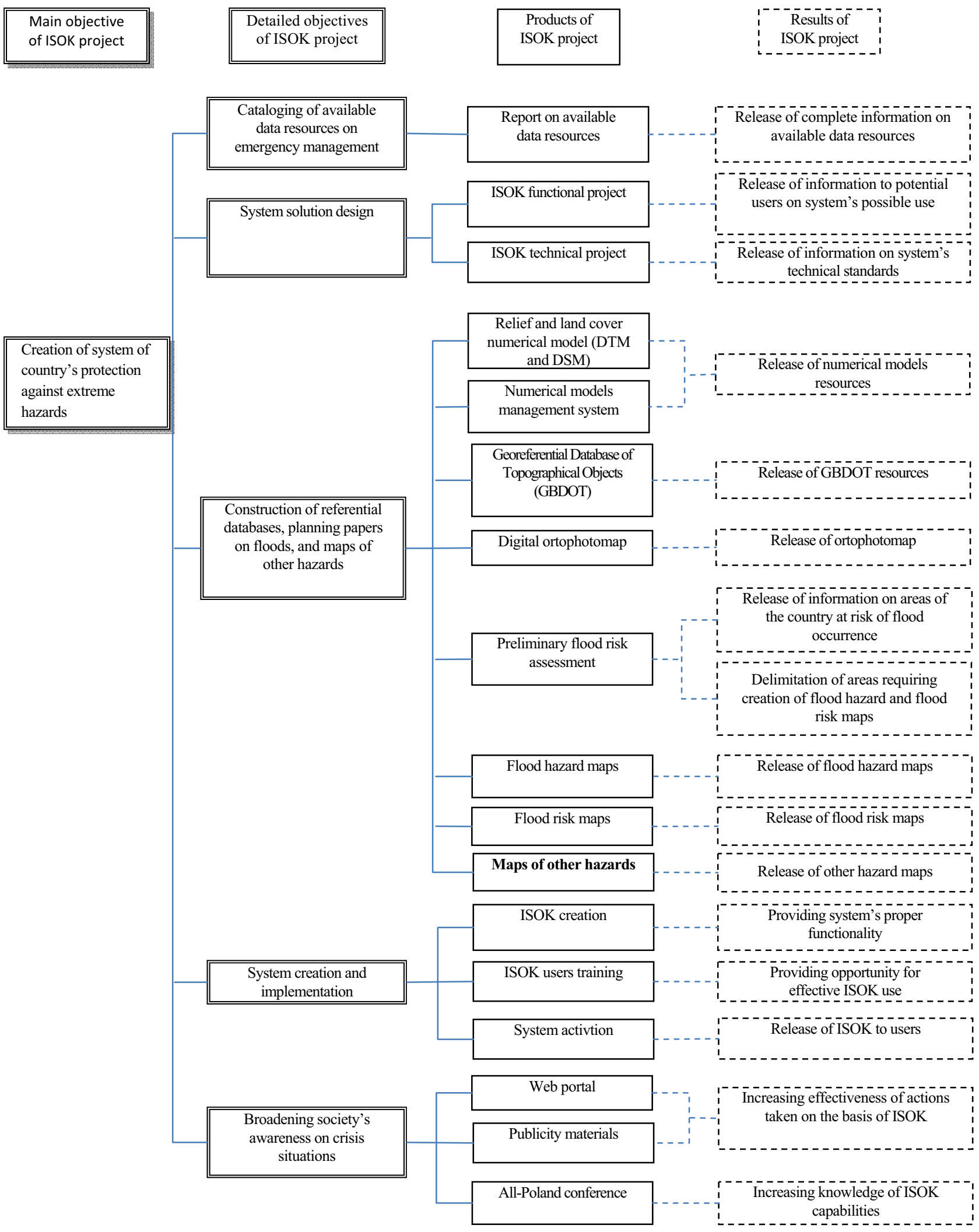

Fig. 1. Location of maps of other hazards with respect to the ISOK project architecture. 
Flood hazard maps

Flood risk maps

Meteorological hazard maps

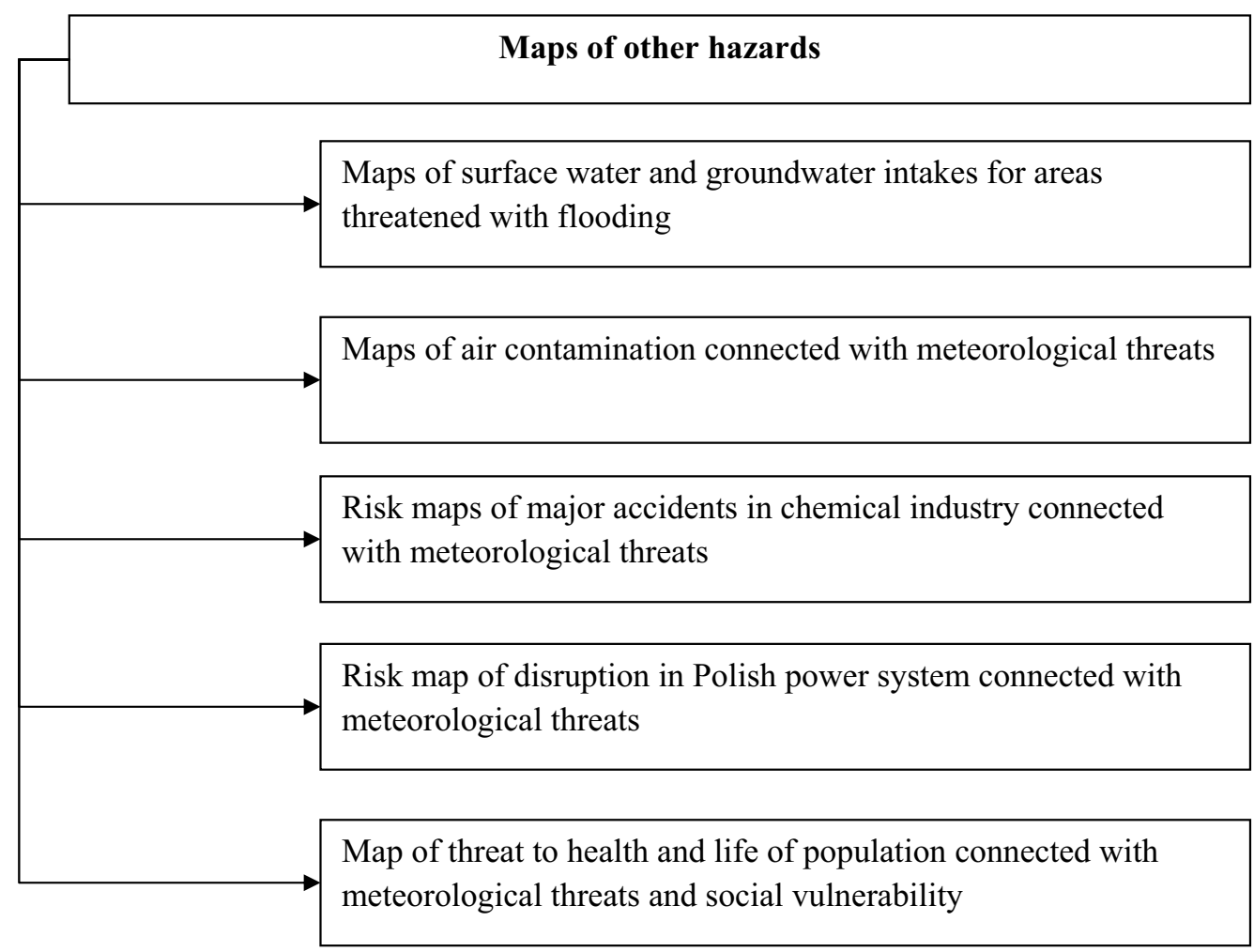

Fig. 2. Maps of other hazards.

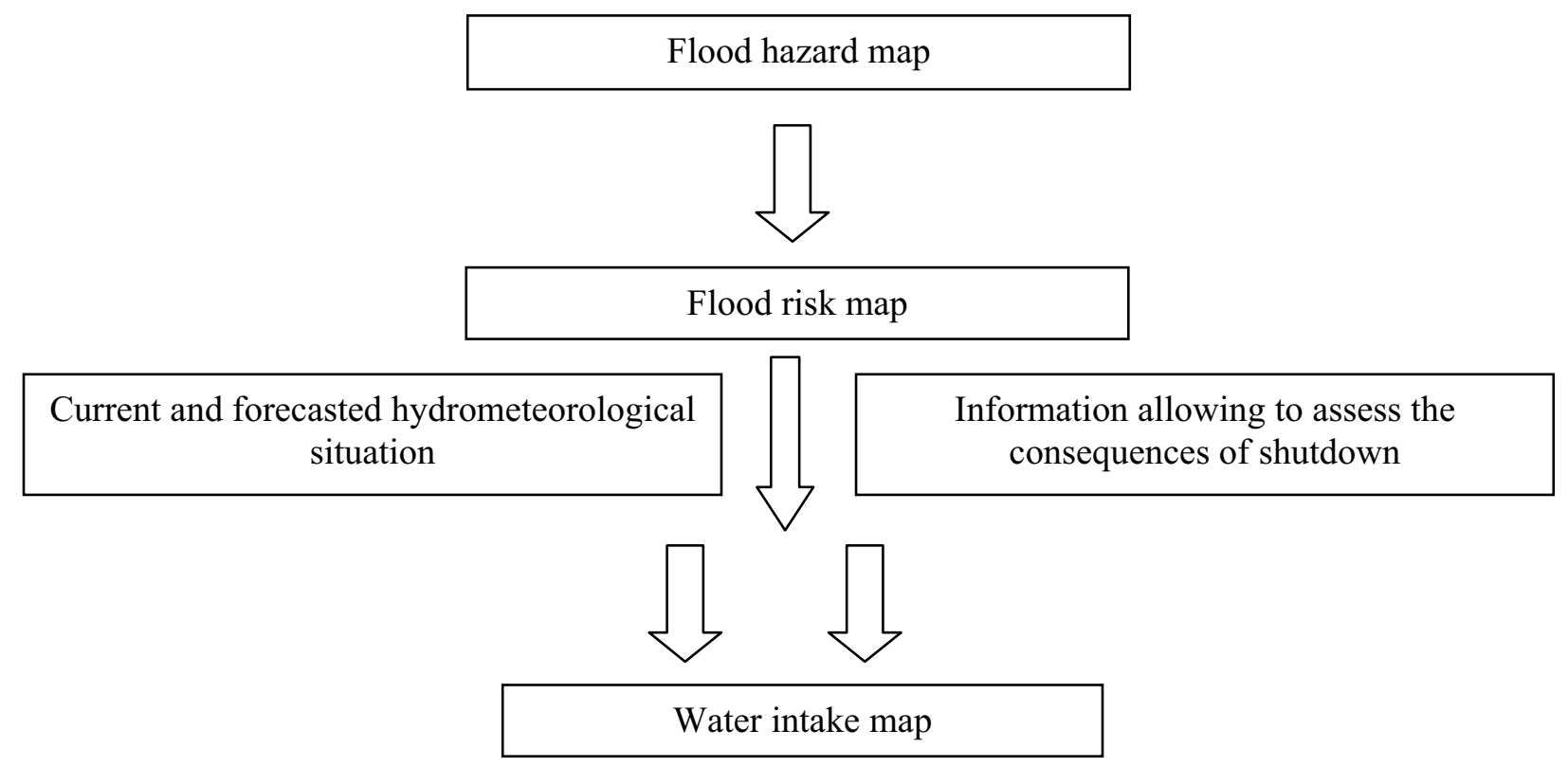

Fig. 3. Water intake maps as extension of flood risk maps. 


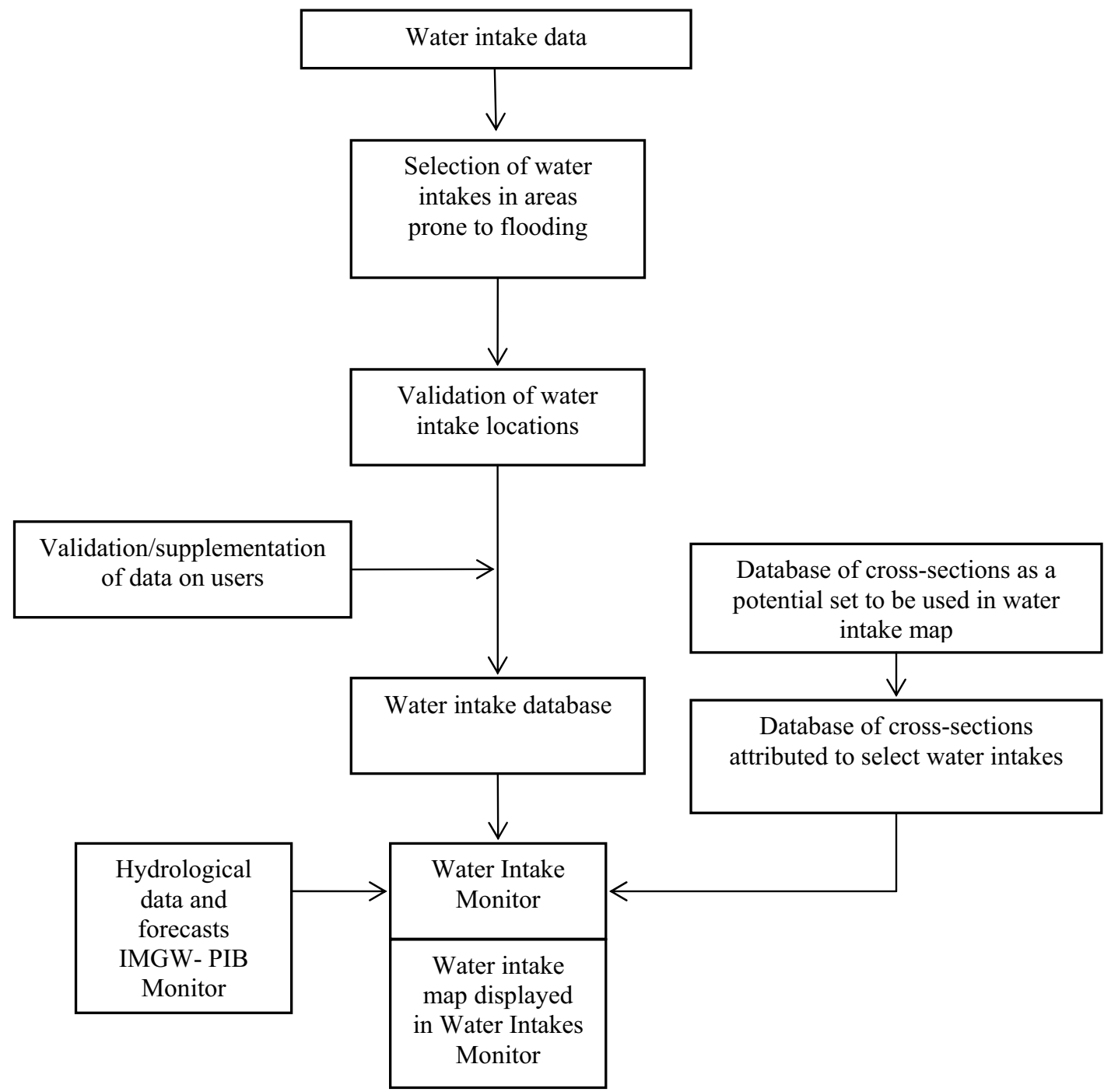

Fig. 4. Chart showing the process of developing water intakes maps.

Water intakes shown on the map include both the intakes defined as facilities, with buildings required for water yielding, as well as other facilities of water supply, including water treatment plants.

On flood risk maps, water intakes are depicted with points, with division into surface water intakes, groundwater intakes, and water treatment plants. In the consolidated spatial database - the basis for the development of flood hazard maps and flood risk maps - each of these objects is supplemented with the information on whether it is in the area of possible inundation for flood scenarios characterized by the streamflow exceedance probability of $\mathrm{Q}_{\mathrm{pmax}=0.2 \%}$, $\mathrm{Q}_{\mathrm{pmax}=1 \%}$, and $\mathrm{Q}_{\mathrm{pmax}=10 \% \text {. }}$

The process for developing a water intake map is described in Fig. 4.

Water intake maps are displayed by the Water Intakes Monitor, an application developed during the ISOK project. Hydrological data and forecasts are obtained from the IMGW-PIB Monitor. This web application was used at the IMGW-PIB to present and display current measurement data and other IMGW-PIB products. The data come from the IMGW-PIB automated measurement network as well as from weather observers. The IMGW-PIB Monitor incorporates a hydrodynamic model built on mass and energy balance equations, which forecast streamflow or water stage with hourly resolution for the nearest three days. The Monitor was created with Internet technologies. It is accessible via web browsers, hence both the Water Intakes Monitor and the IMGW-PIB Monitor can be exploited with the use of any computer or mobile device. The same data, products, and functionalities are available at the same time for IMGW-PIB employees and other authorized users, such as emergency services, national authorities, the military, or fire service.

The Water Intakes Monitor presents the user with a map of overlaid water intakes, gauge stations, and weather stations (Figs. 5a and b). The following links are displayed at the top of the page: 'Map of intakes', 'List of intakes,' 'Log in,' 'Contact form,' and 'Search intakes database' box. The contact form is a vital module of the map. It provides quick and easy exchange of information with the IMGW-PIB map administrator. The form allows, among others, to add a new water intake or a new user.

The water intakes map is set as a homepage. A link to it is also visible in the menu at the top of the page. The loca- 
tions of the water intakes and gauge stations as well as weather stations accompanying them are shown on the map. The open street map is used as a background layer [14]. The window is designed in the following manner: bookmarks in the top-right corner - 'Layers,' 'Legend,' and the full screen mode; and navigation cursors in the top-left corner of the map.

The 'Layers' menu displays the types of objects and the background map. A slide-out window is divided into:

- Objects: water intakes, gauging stations, weather stations
- Background maps: open street map (fresh) and open street map

By selecting an icon representing water intakes, basic specification of an object is shown. On the basis of layers containing location of water intakes and cross-section of streams incorporated into flood hazard maps, cross-sections representing each of the water intakes were chosen. An effort was made to choose a cross-section closest to a given object.

For the Decision Support System and operational use of maps, water intake status is the most crucial information.

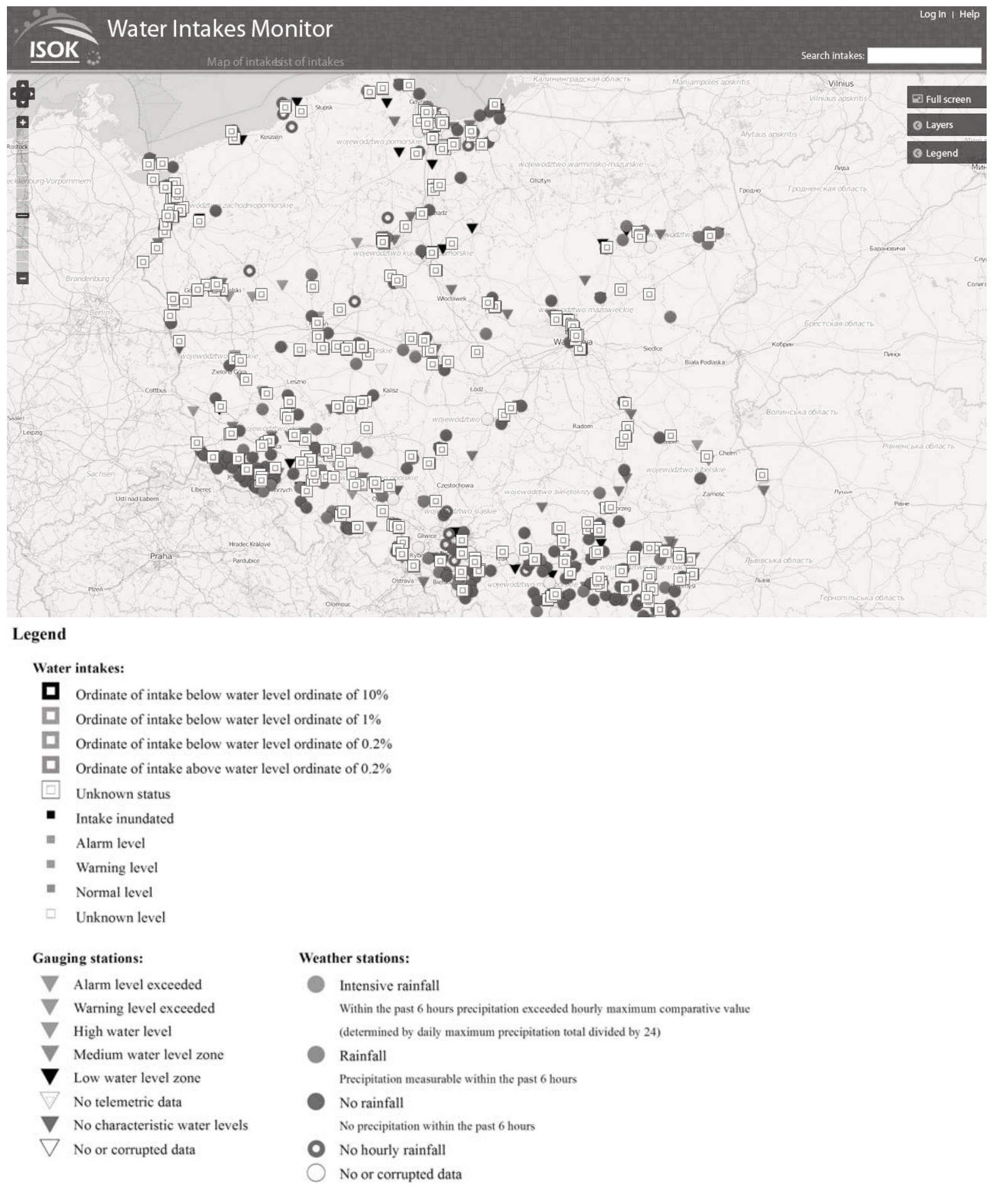

Fig. 5 a) Water Intakes Monitor application screen (source: own elaboration based on IMGW-PIB database); b) Water Intakes Monitor legend (source: own elaboration based on IMGW-PIB database). 
Status is defined by forecasted stream bed filling expressed as a percentage.

The forecasted stream bed filling is calculated as the quotient of the forecasted filling and the relative depth of the water intake, expressed as a percentage.

The relative depth of the water intake is calculated as the difference between zero ordinate of an object with water intake installation, and the ordinate of the lowest point in the stream cross-section.

The forecasted stream bed filling is calculated as the difference between the forecasted filling ordinate, and the ordinate of the lowest point in a stream cross-section.

$$
\begin{aligned}
& G W=R_{z o b}-R_{n p p}[\mathrm{MASL}] \\
& P N=R_{p n}-R_{n p p}[\mathrm{MASL}] \\
& P P N=P N / G W \cdot 100 \%
\end{aligned}
$$

- $\quad P P N-$ forecasted stream bed filling, expressed as percentage [\%]

- $G W$ - water intake relative depth [MASL]

- $R_{z o b}$ - zero ordinate of the object with water intake installation [MASL]

- $R_{n p p}$ - lowest point in a stream cross-section ordinate [MASL]

- $R_{p n}$ - forecasted filling ordinate [MASL]

- $P N$ - forecasted filling [MASL]

Graphical interpretation of water intake status is presented on the map:

- $0 \% \leq \mathrm{PPN}<70 \%$ - normal level - blue inner square

- $70 \% \leq \mathrm{PPN}<90 \%$ - warning level - orange inner square

- $90 \% \leq \mathrm{PPN}<100 \%$ - alarm level - red inner square

- $100 \% \leq$ PPN - water intake inundated - black inner square

Additional facilities shown on the map are gauging stations and weather stations, which form an IMGW-PIBautomated measurement network. The authors of the map decided that, wherever it is possible, a water intake will be associated with at least one gauging station. The observation of water level on a stream gauge gives an additional opportunity to monitor threats and inform the exploiter of the intake and emergency services about a forecasted trend. The trend forecast is depicted both in a graphical form, with the use of arrows, and as a description: rising-, falling-, and no trend.

In the case of weather stations, the users are given additional, tabular information on precipitation that occurred within the past:

- One hour

- Six hours

- 24 hours

Besides, provided for comparison is the information on hourly maximum precipitation and daily maximum precipitation total measured by the weather stations.

The Water Intakes Monitor allows us to display the above-mentioned cross-sections referring to particular intakes. This functionality allows us to show the forecasted water stage and any other stage obtained from manually input data.

Fig. 6 displays water stage forecast, which can reach up to the nearest three days. To achieve this, the user selects day and hour for the forecast. Besides, the application uses animation (which starts after clicking on the 'Play animation' button).

\section{Administration and Use of Water Intakes Map - Discussion of Results}

Administrators of water intakes and the IMGW-PIB content administrator are privileged to edit the properties of a water intake. The edition is accessible from the status of a given intake after choosing the 'Edit' link at right.

The water intake administrator has access to and the possibility to edit administrative data; the content administrator has access to separate information resources in the field of hydrology. Other users will only have access to view the water intake map.

Because the water intake map will provide additional detailed information for flood risk maps, its updating will correspond with the schedule of flood hazard maps and flood risk map updates, that is once every six years [2]. The components should be updated simultaneously, including both information on flood hazards and the potential consequences of intake shutdowns. Consequently, the feature of the application is that new, significant water intakes can be added in a relatively short amount of time.

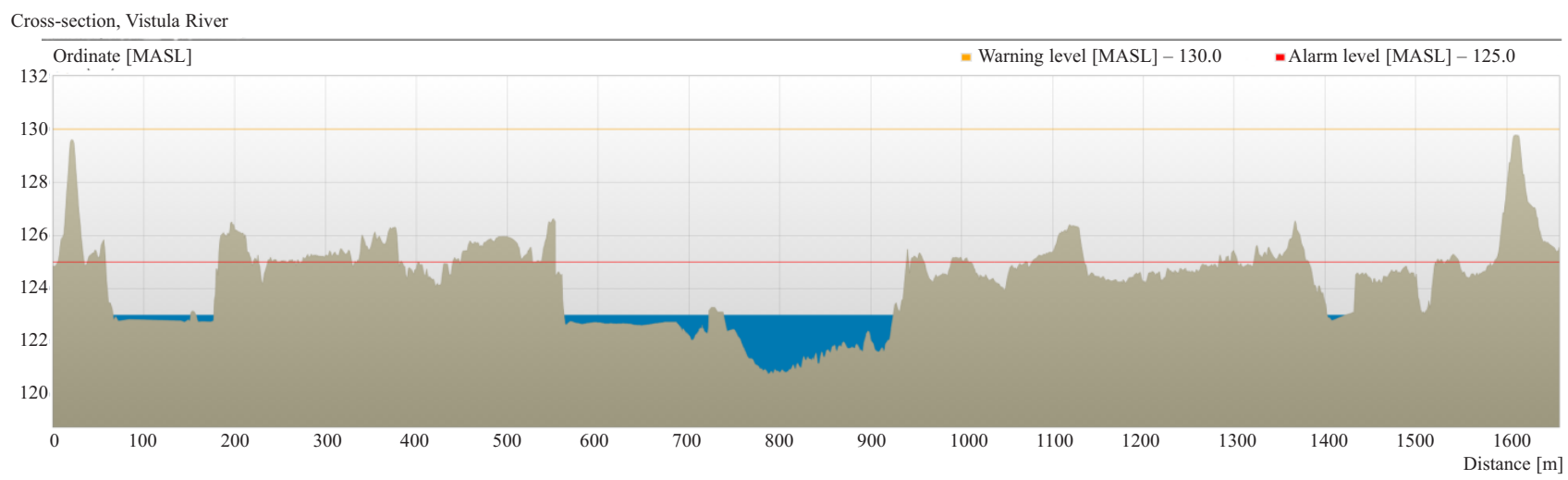

Fig. 6. Exemplary display of stream cross-section in Water Intakes Monitor application (source: own elaboration based on IMGW-PIB database). 
The main users of the map will consist of emergency services, public administration, and the users of water intakes, who will be able to use the published information effectively in order to take relevant actions to cope with flooding, including the responsibility to provide an alternative water supply. The map as a Decision Support System will allow users to make decisions concerning adequate protection of the facilities.

Other users will only be able to view the water intakes map.

Additionally, the information for emergency services and public administration for the area of a voivodeship (province) will be accessible in a report form. The functionality of the danger display in a regional scale may be helpful not only for deciding what actions should be taken, but also to establish the hierarchy.

The way to inform units responsible for emergency management and society about possible consequences of water intake inundation can be represented by the Aarhus Convention [15] on the collection and dissemination of environmental information. Article 5 of the convention states that 'In the event of any imminent threat to human health or the environment, whether caused by human activities or due to natural causes, all information which could enable the public to take measures to prevent or mitigate harm arising from the threat and is held by a public authority is disseminated immediately and without delay to members of the public who may be affected."

The costs of Decision Support System implementation are negligible if compared to possible losses caused by damage to an unprotected water supply infrastructure and water shortages. Within the cost analysis of the system's future maintenance, the following activities, indispensable for the system's proper functioning, were accepted:

- Elaboration of data obtained through surveys among the subjects that exploit water intakes

- Verification and analysis of data obtained through surveys with special attention paid to updating the methodological assumptions

The analyses indicate that when the participation of technical administrator and hydrology specialists is taken into account, total working hours per year that are required for the system's proper functionality will not exceed one vacancy, that is ca. $€ 25,000$.

The Water Intakes Monitor application allows us to show other facilities of critical infrastructure. Currently, an effort is made to supply the monitor with data on the location of industrial establishments mentioned in the Seveso III Directive 2012/18/EC [16], i.e. lower-tier and upper-tier establishments. Using the monitor to inform the society about possible dangers allows safety management implementation, thus reducing danger in order to prevent possible accidents, lower the likelihood of their occurrence, and reduce potential consequences [16].

\section{Conclusions}

The main idea of the map is to present policymakers and owners of the water supply infrastructure the possible consequences of flooding, which requires taking actions, including alternative solutions to the water supply duty. Of great importance for the future development of the Decision Support System is the possibility of expanding its functionality with the analysis of water contamination with substances that can affect the quality of yielded water due to a significant industrial disaster.

The second aspect is critical, since the location of potentially dangerous facilities above water intakes may result in their submergence and the release of dangerous substances and, consequently, contamination of a water intake. During a flood, surface runoff makes a substantial volume of the total runoff at a given drainage basin. The discharge carries bacterial and chemical contamination that are dangerous to human health.

Not only will the water intakes map allow us to monitor and forecast threats, but it will also allow us to observe both the dynamism of changes in a more further-reaching temporal perspective and the frequency of water intake shutdowns. The gradual development of a water intake shutdown database will back the process of decision making in terms of constructional changes to facilities. This will improve their resistance to flooding and, in the most extreme cases, will provide justification for introducing changes to the locations of the constituent objects most vulnerable to flooding. The functionality of the application will allow us in the future to add other objects whose protection is crucial for national security.

Other elements of the critical infrastructure to be added in the future include:

- Energy, energy resources, and fuels supplies

- Telecommunications

- Information and communications technology networks

- Finance

- Food security

- Health care

- transportation

- Emergency services

- Securing permanence of public administration

- Production, storage, safe keeping, and use of chemical and radioactive substances, as well as dangerous goods pipelines

Such elements can be taken into account only if they are located within the range of the flood hazard maps or their updates.

\section{References}

1. Best practices on flood prevention, protection and mitigation, Water Directors meeting, Athens, June 2003.

Available from: http://ec.europa.eu/environment/water/ flood_risk/pdf/flooding_bestpractice.pdf

2. EUROPEAN PARLIAMENT, COUNCIL OF THE EUROPEAN UNION. Directive 2007/60/EC of the European Parliament and of the Council of 23 October 2007 on the assessment and management of flood risks (OJ L288, 6.Nov. 2007).

3. EUROPEAN COMMISSION. Communication from the Commission of 12 December 2006 on a European Programme for Critical Infrastructure Protection (COM/2006/0786 final). 
4. COUNCIL OF THE EUROPEAN UNION. European Council Directive 2008/114/EC of 8 December 2008 on the identification and designation of European critical infrastructures and the assessment of the need to improve their protection (OJ L345, 23 Dec. 2008).

5. EUROPEAN COMMISSION. Communication from the Commission to the European Parliament and the Council for EU Internal Security Strategy in Action: Five steps towards a more secure Europe (COM/2010/0673 final).

6. Available from: www.isok.gov.pl

7. Flood Preparation and Recovery for Drinking Water Systems - Drinking Water Program 5/7/12 DEC Drinking Water, 2012. Available from: http://dec.alaska.gov/eh/docs/ $\mathrm{dw} /$ Security/9.Flood $\% 20$ Packet $\% 20 \% 28$ Final $\% 205-7$ $12 \% 29$.pdf

8. Forward Integration of Flood Warning in Areas Prone to Flash Floods Implementation of a Flash Flood Warning System for Inhabitants and Users of Flood Plain Areas in the Kłodzko Valley, Poland WMO/GWP Associated Programme on Flood Management, 2006. Available from: http://www.apfm.info/projects/pilot/europe/Flash_Flood_ Poland_Pilot.pdf

9. BARREDO J. I. Normalised flood losses in Europe: 19702006, Natural Hazards \& Earth System Sciences; 9, (1), 97, 2009.

10. MACIEJEWSKI M., OSTOJSKI M., WALCZYKIEWICZ
T. Vistula river basin - floods monograph May-June 2010; ISBN 978-83-61102-59-5; IMGW Warsaw; 1-236, 2012 [In Polish].

11. Available from: www.pis.gov.pl

12. BÉROD D., DUFOUR F., FREDE V., GERBER M., HEGG CH., HILKER N., OPLATKA M., ROMANG H., RHYNER J., ZAPPA M. IFKIS-Hydro: an early warning and information system for floods and debris flows. Nat. Hazards, 56, (2), 509, 2011.

13. ALFIERI L., PAPPENBERGER F., SALAMON P., THIELEN J., WETTERHALL F. Operational early warning systems for water-related hazards in Europe Environmental Science \& Policy, 21, 35, 2012.

14. Available from: http://www.openstreetmap.org

15. COUNCIL OF THE EUROPEAN UNION. Council Decision of 17 February 2005 on the conclusion, on behalf of the European Community, of the Convention on access to information, public participation in decision-making and access to justice in environmental matters (OJ L124, 17 May 2005).

16. EUROPEAN PARLIAMENT, COUNCIL OF THE EUROPEAN UNION. Directive 2012/18/EU of the European Parliament and of the Council of 4 July 2012 on the control of major-accident hazards involving dangerous substances, amending and subsequently repealing Council Directive 96/82/EC (OJ L197, 24 Jul. 2012). 
